\title{
The Effect of Addition of Rubber Leaf Powder to Empty Fruit Bunch (EFB) Bio-briquettes Binderless
}

\author{
Nofriady Handra ${ }^{*}$, Anwar Kasim² ${ }^{2}$ Gunawarman ${ }^{3}$, Santosa $^{2}$ \\ \{nof.hand11@gmail.com\} \\ ${ }^{1}$ Department of Mechanical Engineering, Institut Teknologi Padang, Padang, Indonesia \\ ${ }^{2}$ Faculty of Industrial Agriculture Technology, Andalas University, Padang, Indonesia \\ ${ }^{3}$ Mechanical Engineering Department, Andalas University, Padang, Indonesia
}

\begin{abstract}
Biomass development has been an essential issue for the past few decades and will remain attractive in the future because of its clean, renewable, carbon-neutral, and other advantages. The goals of this study are to obtain the effect of adding rubber leaf powder to the manufacture of binderless briquettes, especially on the quality of the bio-briquettes produced and the calorific value. Comparison of the composition of EFB to rubber leaf powder varied at 5:95\%, 10: 90\%, 15:85\%, 20:80\%, and 100\% EFB fiber. The heating temperature is varied at $155^{\circ} \mathrm{C}$, up to $195^{\circ} \mathrm{C}$ with a holding time of 20 minutes. At a mixture percentage of $95 / 5 \%$ (fiber/powder), it is a good composition when compared to other percentages. The test results showed that the heating temperature and the use of the composition of the EFB with rubber leaf powder had an effect on increasing the heating value, toughness, and duration of the briquette ignition.
\end{abstract}

Keywords: Bio-briquette, EFB, fiber, binderless, calorific value

\section{Introduction}

It has been a carbon-neutral problem for many decades, and the growth of biomass, with its clean, renewable, and carbon-neutral characteristics is expected to continue to be a desirable option in the future. Increased concern over growing reliance on environmental and energy issues has turned into a motivator for expanding the use of bioenergy as a replacement for fossil energy in the future, both for space heating and as a power plant. Using fiber and empty fruit bunches (EFB) as alternative energy sources, researchers have conducted lab and pilot-scale studies on technical innovation in both the food and beverage industries. Using the processes of conventional combustion, gasification, and charcoal briquettes, researchers have investigated the potential of fiber and EFB as a source of energy [1]. The use of agricultural waste as a source of alternative energy is one example [2]. Coal and biomass are examples of alternative energy sources that may be developed as a replacement for fossil fuels. Coal is a fossil fuel that provides energy, while biomass is a natural component that is often considered waste and is frequently destroyed by burning. Agriculture waste may be converted into a solid fuel that can be used as an alternative fuel, known as bio-briquettes, in large quantities. EFB are bunches of fresh fruit palm oil that have been separated from the rest of the oil. It achieves 24.1 percent of the Fresh Fruit Bunches (FFB) that are to be processed in terms of EFB. The use of EFB as an energy source in the form of charcoal briquettes would not only provide financial advantages, but it will also aid in the preservation of the environment. EFB, also known as cellulosic biomass, may be converted into charcoal via a very easy procedure. biomass energy has attracted attention as a potential alternative because it is an ideal renewable energy source with several advantages such as lower sulfur content, abundant availability generally in the form of agricultural waste and 
other 2 sources, and lower cost than in addition to other renewable energy sources This renewable form of energy, which may be generated from biomass, has enormous potential and is also very ecologically benign. It may aid in the mitigation of the growing environmental, economic, and technical problems associated with the depletion of fossil fuels [3].

Numerous research have shown that briquettes are one of the most promising solutions for easing these issues. In general, the technique may be described as a densification process that is used to improve the handling qualities of the raw material while simultaneously increasing the volumetric calorific content of the biomass. [4] A significant amount of study has been done on the briquette technology [4].

On the basis of raw materials and binders, operating temperature and pressure, and treatments, the impact of densified palm biomass combustion characteristics such as calorific value, moisture content, and ash content are discussed. Individual parts were linked to the review in terms of burning rate, which is also included in the review [5].

Empty bunches have been processed into solid briquettes in the form of fine powder particles, which has been successfully accomplished. It's simply that the biomass briquettes that are created still need the usage of adhesives throughout their manufacturing. Briquettes were also created in this research without the usage of any adhesives throughout the process of their creation. The technique used is a heating system in the mold that is operated for a set period of time in order to create briquettes of the highest possible quality in terms of structure, combustion quality, heating value, and toughness.

\section{Material and Method}

The material used is Empty Fruit Bunch. As the basic ingredient of making bio-briquettes is by utilizing EFB waste obtained from the palm oil processing industry in the area of West Pasaman, West Sumatera. The use of EFB is a major factor in obtaining good quality briquettes, especially by selecting fresh and new EFB conditions. The waste treatment has been carried out in several stages before the experiment process of making briquettes was carried out. Waste EFB used in this experiment, as shown in Figure 1.
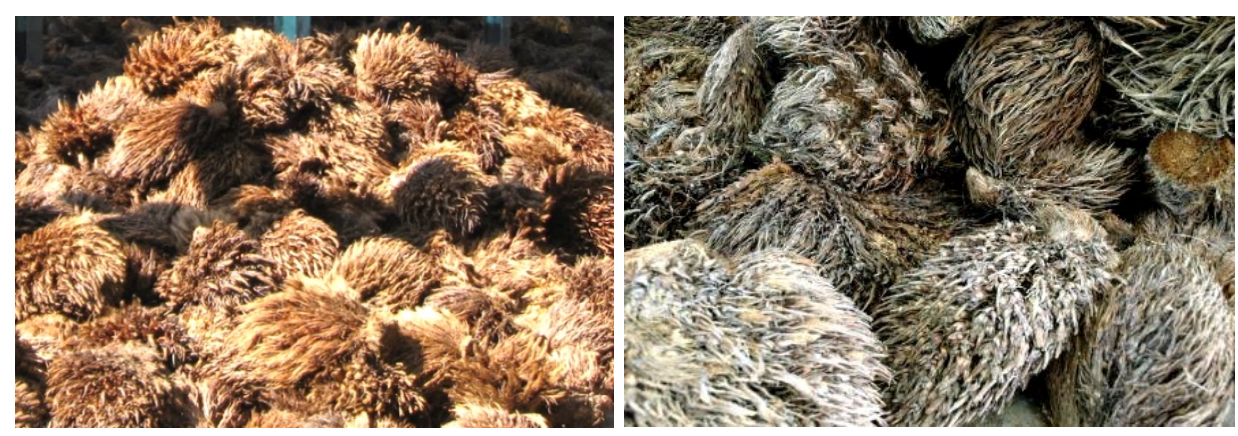

Fig. 1. EFB waste as the basic material for making bio-briquettes

The EFB was dried in the open sun for many days. Enumeration of fibers should be done manually until the size of fineness of the fiber is 20 mesh, after which it should be automated. After the fibers have been cut, they create a range of sizes that are not consistent in different sizes, as well as certain goods in the form of powder. In Figure 2, you can see the powdered EFB and fiber mixture. The fibers that have been chopped into bits are next filtered through the MilanoItaly Aperture 850 Mic 20 mesh to ensure that they are of uniform size 


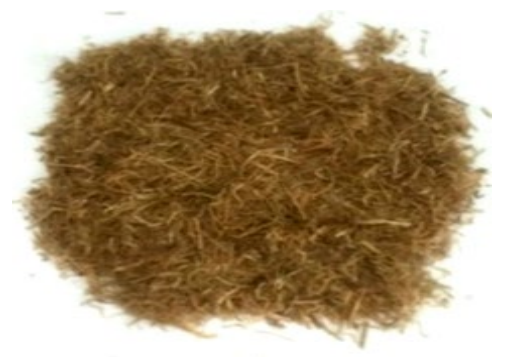

Figure 2. Empty Fruit Bunch after being cut and sieved in 20 mesh

Both the primary leaf stalk and the sapling are part of the rubber leaf's overall structure. Calf leaves are $3-10 \mathrm{~cm}$ in length, while the main leaf stem is $3-20 \mathrm{~cm}$ in height. On a rubber leaf, there are typically three leaflets present. In this case, the elliptical leaflets are elongated, and the edges are flat and pointed at one end. In addition, there are interactions between nutrients and variations between clones, which necessitates the determination of the optimal point and critical point of leaf nutrient content in relation to tree development and maximum yield. In Figure 3, you can see rubber plant leaves. Added to a combination of EFB fiber and rubber leaf powder, rubber leaf powder serves as an antioxidant.

It is necessary to modify the quantity of rubber leaf powder used in relation to the percentage of EFB fiber. To determine the impact of these components on the mechanical, physical, and fuel values of briquettes, rubber leaf powder was added to the mixture to test them. As shown in Table 1, the rubber leaf has a chemical makeup that contains a variety of components.
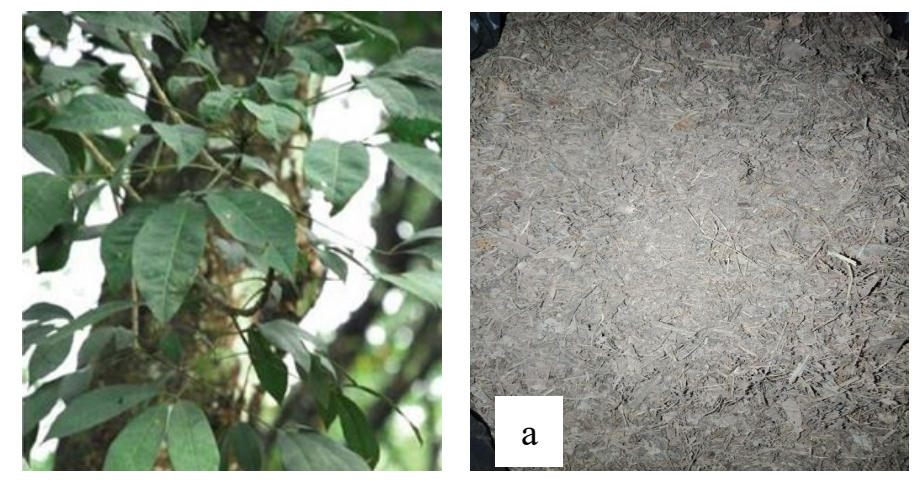

Fig. 3. Rubber plant leaves (a), and crushed rubber leaf powder (b)

Table 1. Chemical Composition of Rubber Leaves

\begin{tabular}{cll}
\hline No & Chemical Composition & Composition (wt\%) \\
\hline 1 & Lignin (\%) & 53,23 \\
2 & Selulosa (\%) & 31,15 \\
3 & Hemiselulosa (\%) & 15,07 \\
4 & Ash (\%) & 17,25 \\
5 & Water content (\%) & 8,986 \\
\hline
\end{tabular}


Methods

The typical mold pressure is 58 pounds per square inch (Psi). It is expected that the heated fiber would undergo a process of compaction both chemically and physically throughout the majority of the holding period. When it comes to the binderless briquet process [6,] briquetting pressure and temperature, as well as coal moisture content, are all essential parameters to consider. Briquettes were used as one of the support moldings in this experiment. Briquettes are formed in a mold according to a predefined categorization system. The operating procedure for this mold is to press one part of suppressant till the desired density is achieved. The technique used in this study employs one unit of briquette molding, with a heating system installed on the mold cylinder wall to maintain a constant heating temperature of 200 degrees Celsius while varying the holding duration for 15, 20, and 25 minutes, as shown in Figure 4.

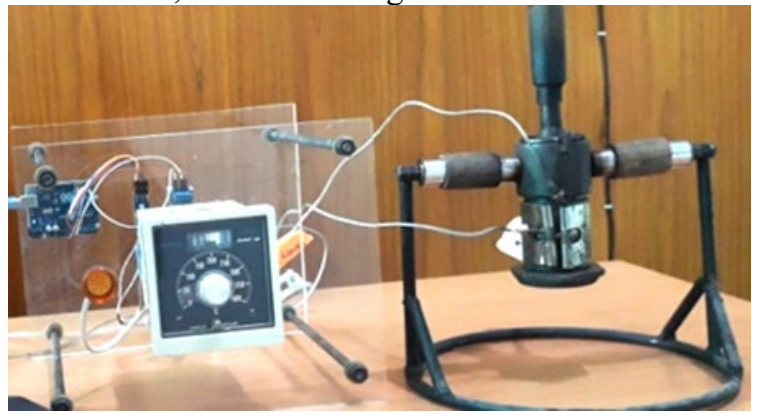

a

b

Figure 4. Heater systems using the thermal controller (a), and mold of briquettes with heater (b) The temperature at which densification occurs is a significant element that may influence the combustion characteristics, particularly the calorific value. According to [7], when working temperatures are high compared to raw material temperatures, the calorific value of densified products rises in comparison to the raw material value. The hardness and heat value tests, as well as the ash and charcoal content tests, are included in the sample. In his presentation, Cattaneo said that briquettes are made by compressing raw materials into tiny logs with a diameter ranging from 30 to $100 \mathrm{~mm}$ and a length varying depending on the technique employed, which may be either screw or piston compression [8]. When it comes to manufacturing high-quality briquettes, many factors like as strength and durability must be taken into consideration [9]. One of the supporting unit components for the study process of creating EFB bio-briquette fiber samples is shown in the illustration above (figure 3). Briquettes are formed in a mold according to a predefined categorization system. The operating procedure for this mold is to press one part of suppressant till the desired density is achieved. The mold has a cylinder form with a total length of $100 \mathrm{~mm}$, a diameter of $40 \mathrm{~mm}$, and a height of $50 \mathrm{~mm}$ for the resultant high-briquettes. The volume of a briquette is calculated by the formula [10], [3]:

$\mathrm{V}=\pi \mathrm{r} 2 . \mathrm{t}(1)$ 


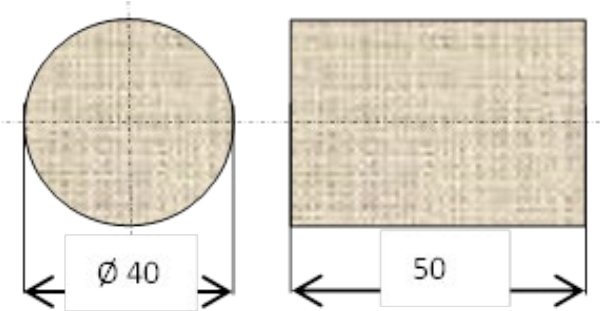

Figure 5. The dimension of the briquette sample.

Bio-briquettes with densities more than $1000 \mathrm{~g} / \mathrm{cm} 3$ are produced by the majority of technical procedures, and they sink in water as a quality control measure. The physical upper-density limit for lignocellulosic materials is about $1500 \mathrm{~g} / \mathrm{cm} 3$, according to the International Union of Pure and Applied Chemistry. The method of applying high pressure to the mold, such as mechanical pistons, pellet presses, or screw extruders, results in a more compact briquette structure in the range of density $1200-1400 \mathrm{~g} / \mathrm{cm} 3$, which is ideal for briquette production. The hydraulic piston pushes the briquette, resulting in less dense bio-briquettes, sometimes weighing less than 1000 $\mathrm{kg}$. Creating and producing bio-briquettes that are excessively thick will not be successful since the combustion characteristics of the briquettes will be compromised.

\section{Results and Discussion}

Briquettes made from biomass. This study is referred to as biomass briquette, and it is simply the process of turning agricultural waste into biomass briquette that is being investigated. Densification may be achieved using any of the elements in the composition that include lignite, ash, and cellulose as constituents. The fundamental idea of this study is to develop materials such as bio-briquettes, which are produced from EFB waste and have a high calorific value in order to generate energy. EFB, being an organic substance, has a fundamental feature shown in the form of physical and chemical characteristics. Empty Fruit Bunch exhibits the following physical and chemical characteristics, as shown in Table 2.

Table 2. Chemical Composition of EFB

\begin{tabular}{clc}
\hline & $\begin{array}{l}\text { Chemical } \\
\text { No }\end{array}$ & Components \\
\hline 1 & Lignin & $15-17$ \\
2 & Cellulose & $36-42$ \\
3 & Hemicellulose & $25-27$ \\
4 & Ash & $0,7-6$ \\
\hline
\end{tabular}

\section{Containment of Water}

The amount of moisture present in a combination of EFB fiber and rubber leaf powder has a significant impact on the quality of the briquettes that are generated. Briquettes with a low moisture level will have a higher heating value than those with a high moisture content. The lower the heating value of a combination of EFB fiber and rubber leaf powder, the greater the water content of the mixture is. This is owing to the fact that the heat produced is first utilized to evaporate the water in a combination of EFB fibers and rubber leaf powder before being converted into heat that can be used as combustion heat in the process. In other words, the 
moisture content of the briquettes will be exactly proportional to the amount of heat produced when they are burned.

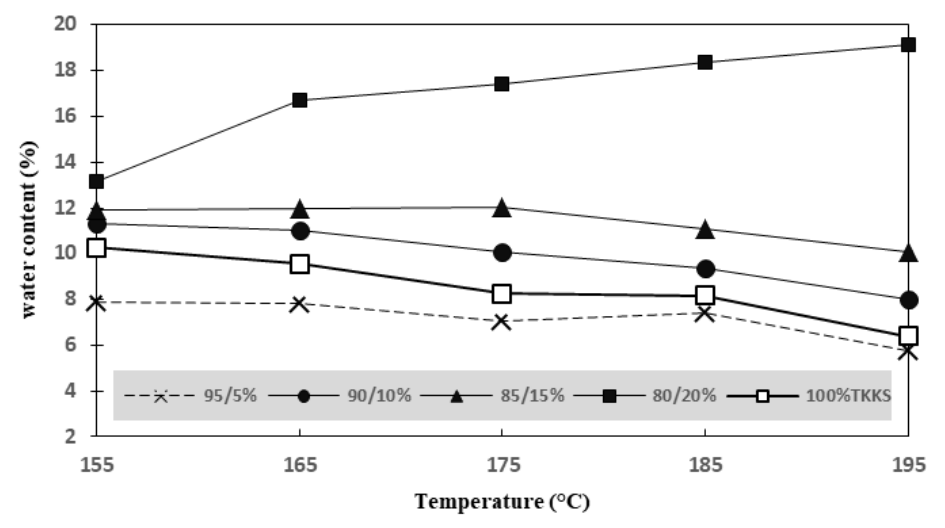

Figure 6. Graph of the relationship vs. water content in briquettes with variations in heating temperature

When a mixture of EFB fibers and rubber leaf powder with a 95/5 percent moisture content is prepared at $155^{\circ} \mathrm{C}$, the highest moisture content is obtained, and the lowest moisture content is obtained at $195^{\circ} \mathrm{C}$ with a moisture content of 5.78 percent. The graph in Figure 6 shows that the highest moisture content is obtained at $155^{\circ} \mathrm{C}$ with a moisture content of 7.88 percent, and the lowest moisture content obtained at $195^{\circ} \mathrm{C}$ with a moisture content of 5.78 percent. At temperatures ranging from $155^{\circ} \mathrm{C}$ to $185^{\circ} \mathrm{C}$, variations in the value of water content do not exhibit statistically significant differences in increments.

The greatest water content was found at a temperature of $155^{\circ} \mathrm{C}$, with a water content of 11.9 percent, and the lowest was found at $195^{\circ} \mathrm{C}$, with a moisture content of 8 percent, for a composition of $90 / 10$ percent. It is possible to get the greatest moisture content at $175^{\circ} \mathrm{C}$ with a water content of 12 percent, and the lowest moisture content at $195^{\circ} \mathrm{C}$ with a water content of 10.1 percent while using an $85 / 15$ percent composition. In the meanwhile, at $80 / 20$ percent, the greatest water content was found at a temperature of $195^{\circ} \mathrm{C}$, with a value of 19.12 percent, and the lowest was found at a temperature of $155^{\circ} \mathrm{C}$. According to these results, 100 percent of EFB fiber content has the greatest water content at $155^{\circ} \mathrm{C}$ with a moisture content of 10.3 percent, while the lowest water content is found at $195^{\circ} \mathrm{C}$ with a moisture content of 6.4 percent, according to these results. According to the findings of the tests, the higher the temperature is set in the process of producing briquettes from an amalgam of rubber leaf powder, the greater the amount of water content will decrease as the heating temperature is raised. It is an excellent composition when compared to other percentages, with a combination proportion of $95 / 5$ percent (fiber/powder). The quantity of water content in the rubber leaf powder will rise according to the amount of rubber leaf powder supplied.

\section{Numerical Calorific Value}

One of the most significant properties of a fuel is its calorific value, which is defined as the amount of energy released per kilogram of the fuel when it is consumed. As a result, the calorific value of a processed fuel may be used to determine the competitiveness of that fuel in a particular market scenario. However, there are a variety of other variables that affect the 
market value, including ease of handling, burning characteristics, and so on. However, the While the calorific value is by far the most important element to examine, it should also be taken into account when selecting the raw material input. The numbers [11] and [12] are the ones to remember.

A considerable effect is exerted on the quality of the bio-briquettes produced by EFB fiber depending on the amount of moisture present in the fiber. In general, bio-briquettes with a low water content produce higher heat values than those with a high water content, and this specific briquette is manufactured from a kind of fiber that naturally has a low moisture content. As the quantity of water in the briquettes rises, the calorific value of the briquettes falls proportionally. Due to the fact that the heat generated is first required to evaporate water from the fiber before being converted to heat that may be used for combustion, this is the case. In other words, the amount of water present has a direct relationship with the heating value. The calorific value of briquettes is what defines their quality. The greater the heat value, the higher the quality of the briquettes that are manufactured. It is possible to improve heating values when the water content, ash content, and volatile matter are low. It is possible that a high carbon content may enhance heating values.

The calorific value test is intended to evaluate the degree to which the value of combustion heat generated by briquettes may be quantified. The temperature at which densification occurs is a significant element that may influence the combustion characteristics, particularly the calorific value. Increasing the calorific value of densified products as compared to the calorific value of raw materials occurs when the operating temperature is higher than the normal operating temperature. According to Figure 7, data analysis was carried out to determine the connection between the heating value produced and the heating temperature.

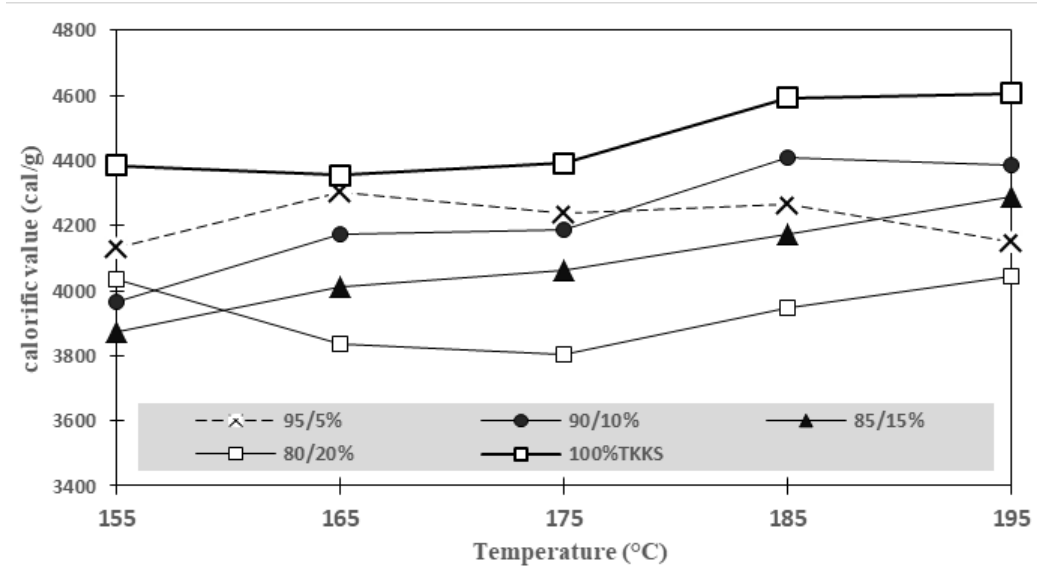

Fig. 7. Graph of the relationship between the heating value and the heating temperature of each composition variable.

The calorific value of the briquettes is what defines their overall quality. The greater the heating value, the higher the quality of the briquettes that are manufactured. The heating value may be increased by having a low water content, a high ash content, and a high amount of volatile materials. High carbon content has the potential to raise the heating value. The calorific value of the briquettes is being measured in order to establish the extent of the combustion heat value generated by the briquettes. The Oxygen X-ray Calorimeter is used to determine the heating 
value of the sample. The ASTM D-5865-01 standard was used to develop the method for determining the heating value. Figure 7 indicates that an average temperature of $185^{\circ} \mathrm{C}$ and $195^{\circ} \mathrm{C}$ enhanced the heating value in the combination of EFB fibers and rubber leaf powder at a composition of $95 / 5$ percent for all combined variables, with the exception of the composition of $95 / 5$ percent. Meanwhile, the heating value of the 100 percent briquette fiber was the greatest of all the briquettes created, outperforming all the others.

\section{Conclusions}

Using trash as an alternative energy source may help to minimize pollution to the environment by generating goods such as bio-briquettes that are utilized by the community and can be recycled. It is an excellent composition when compared to other percentages, with a combination proportion of $95 / 5$ percent (fiber/powder). The quantity of water content in the rubber leaf powder will rise according to the amount of rubber leaf powder supplied. The temperature at which densification occurs is a significant element that may influence the combustion characteristics, particularly the calorific value. Using a composition of $90 / 10$ percent and heating it to $185^{\circ} \mathrm{C}$, the maximum heating value generated was $4410.76 \mathrm{cal} / \mathrm{g}$ at a temperature of $185^{\circ} \mathrm{C}$.

\section{Acknowledgment.}

The authors would like to thank all those who have helped and supported this research, especially to the Institut Teknologi Padang Mechanical Engineering laboratory and Andalas University Agroindustry Laboratory and staff.

\section{References}

[1] Sri. W, L. Firman, Sahwan, S. Feddy, 2008. J. Tek. Ling. 64.

[2] Nicholas. A.M. Folorunsho. O.A, 2012. ETASR Eng, Tech. \& Application. Science. Res., 2 pp; 265.

[3] Nofriady. H, Anwar. K, Gunawarman, Santosa. J. Ijaseit. 8, 2018 pp; 1071.

[4] Wilaipon. P, 2009. J. American App. Sci. 6, pp; 167.

[5] Faizal. H.M, Rosdzimin, M, Rahman. A Latiffa. Z.A, 2016. J. Tech. 78 pp; 9.

[6] Boalin. S, Jianglong, Y, Arash. T, Yanna. 2014. H, J. Fuel Proc. Tech. 124 pp; 243.

[7] Nasrin. A.B, Ma. A.N, Choo. Y.M. Mohamad. S. Rohaya. M.H, Azali, A, Zainal. Z, 2008. American J. App. Sci. 5 pp; 179.

[8] Cattaneo. D, 2003. Wood Energy. Univ. of Brescia.

[9] Faizal. H.M, Latiff. Z.A, Mazlan, Wahid. A Darus. A.N. New Aspects of Fluid Mechanics, Heat Transfer, and Environment, 1792.

[10] Basar. K, Sakuma. T, Kartini. E., 2006. Proceedings of the International Conference on Mathematics and Natural Science, pp; 881.

[11] Faizal, H.M., Rosdzimin, M., Rahmanb, A., and Latiffa. Z.A. 2016. Review on Densification of Palm Residues as a Technique for Biomass Energy Utilization. J. Teknologi. 78: 9-2 9-18.

[12] Aditya Kurniawan. 2015. Analysis of Combustion Characteristics of Palm Oil Industrial Waste Briquette Varying Temperature Adhesives and $300 \mathrm{C}$ Wall Furnaces, $400{ }^{\circ} \mathrm{C}$ and $500{ }^{\circ} \mathrm{C}$ Heat Flux Method Using Constant (Hfc). 